\title{
Characterization of RUSI, a telomere-associated satellite DNA, in the genus Rumex (Polygonaceae)
}

\author{
R. Navajas-Pérez ${ }^{\mathrm{a}} \quad$ T. Schwarzacher ${ }^{\mathrm{b}} \quad$ M. Ruiz Rejón ${ }^{\mathrm{c}} \quad$ M.A. Garrido-Ramos ${ }^{\mathrm{c}}$

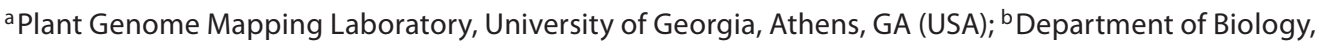 \\ University of Leicester, Leicester (UK); ' Departamento de Genética, Facultad de Ciencias, Universidad de Granada, \\ Granada (Spain)
}

\begin{abstract}
A satellite-DNA family (RUSI) has been isolated and characterized in Rumex induratus Boiss and Reuter (Polygonaceae), an Iberian endemic polygamous sorrel. The RUSI repeats are 170 bp in length and $\sim 68 \%$ AT-rich containing different variants of degenerate telomere motifs - $(\mathrm{TT})_{n} \mathrm{AN}(\mathrm{GG})_{n}-$, a typical feature of subtelomeric DNA repeats adjacent to telomeres, which have been referred to as telomere-associated sequences or TASs. In fact, fluorescent in situ hybridization showed that this satellite DNA is located in subtelomeric positions of most of the chromosomes of $R$. induratus, with some centromeric loci. PCR and Southern-blot hybridization assays for sequence conservation in the genus Rumex, indicated that the RUSI sequences are restricted to the genomes of $R$. induratus and $R$. scutatus, both species of the section Scutati, suggesting that they are recently evolved. Sequence variation within the two species is high (mean value of sequence differences between repeats of $15 \%$ for $R$. induratus and $7.5 \%$ for $R$. scutatus) and the degree of sequence differentiation between species is low with no species-specific variants, postulated to be due to slowed rates of spreading of sequence variants by molecular homogenizing mechanisms. Characteristics of RUSI sequences are discussed in the light of their chromosomal location and analyzed for their evolutionary and phylogenetic implications.
\end{abstract}

Copyright $\odot 2009$ S. Karger AG, Basel
Rumex (Polygonaceae) is a plant genus containing dioecious, gynodioecious, polygamous and hermaphroditic species (Rechinger, 1964). Many scientific programs have focused on this genus because of its biological and evolutionary significance in sexual dimorphism. Within the genus Rumex three phylogenetic clades can be defined (Navajas-Pérez et al., 2005a; Fig. 1). The basal clade is composed of hermaphroditic docks, while the second comprises polygamous/gynodioecious sorrels and the third dioecious sorrels except for one hermaphrodite, this latter clade containing species with different sexdetermination systems (XX/XY and XX/XY $\left.\mathrm{XY}_{2}\right)$. Polygamous and gynodioecious sorrels have important evolutionary significance because they are intermediate forms on the way toward the evolution of separate sexes (Navajas-Pérez et al., 2005a) and could help unravel the origin of dioecy and sex chromosomes in Rumex species. Furthermore, these species have applied interests in medicine (Rivera and Obón, 1995), as a dietary source of potential bioactive compounds (Ferreres et al., 2006) or have been proposed as candidates for $\mathrm{Hg}$ phytoremedia-

This research was supported by grant CGL2006-00444/BOS awarded by the Ministerio of Educación y Ciencia (Spain), and Fondo Europeo de Desarrollo Regional (FEDER, EU). R.N.-P. is a Fulbright postdoctoral scholar (FU-2006-0675) supported by Spanish MEC.

\section{KARGER \\ Fax +4161306 1234 \\ E-Mail karger@karger.ch}

www.karger.com
C 2009 S. Karger AG, Basel

$1424-8581 / 09 / 1241-0081 \$ 26.00 / 0$

Accessible online at:

www.karger.com/cgr
Rafael Navajas-Pérez

Current address: Departamento de Genética, Facultad de Ciencias

Universidad de Granada, Granada (Spain)

telephone: +349582430 80; fax: +34 9582440 73; e-mail: rnavajas@ugr.es 


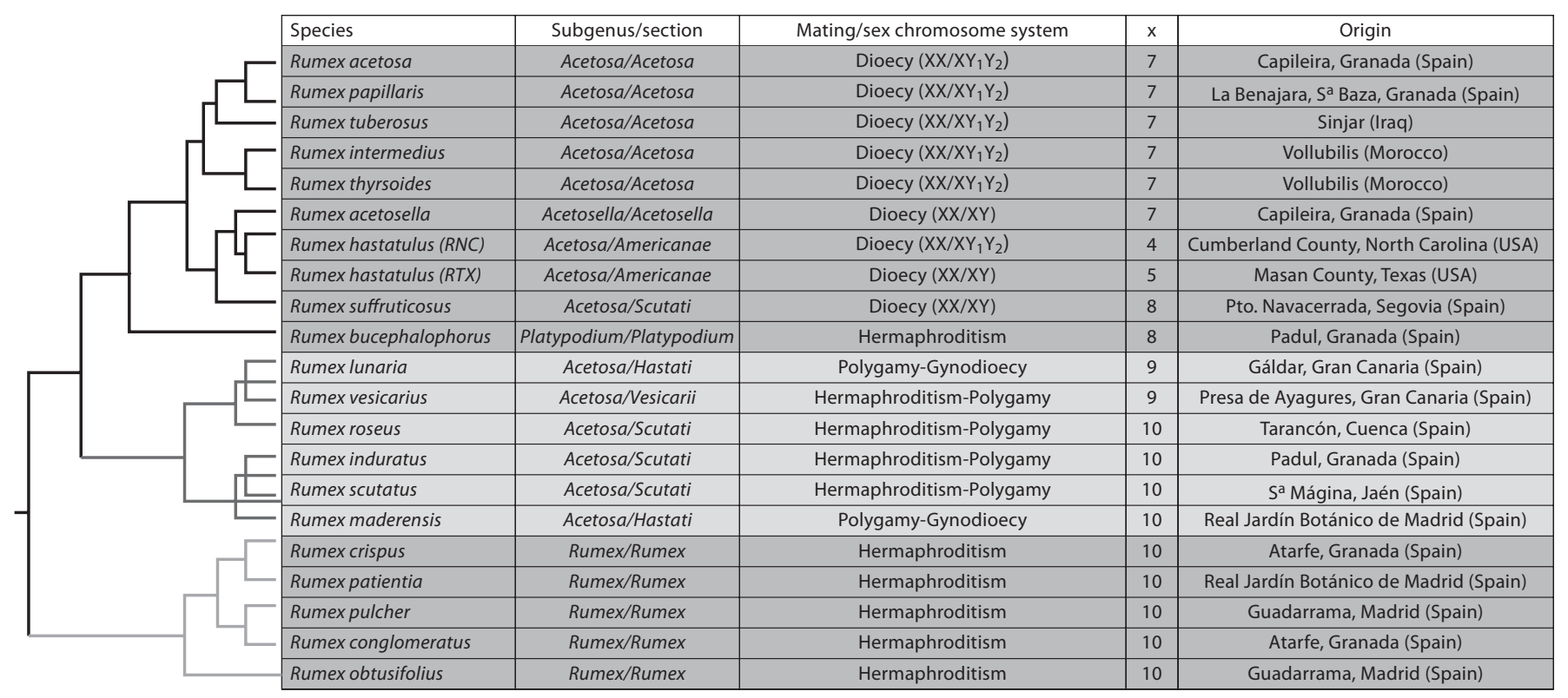

Fig. 1. List Rumex species analyzed in this paper, indicating their affiliations, mating/sex chromosome system, basic chromosome number (x), and their phylogenetic relationship (left - based on Navajas-Pérez et al., 2005a).

tion of contaminated soils (Moreno-Jiménez et al., 2006). In this context, we are interested here in the cytogenetic and molecular analysis of Rumex induratus Boiss and Reuter (Polygonaceae), an Iberian endemic polygamous sorrel. Ultimately, we aim to understand the phylogenetic aspects of sequence and chromosomal evolution in Rumex using DNA markers to study the processes involved in karyotype and sex-chromosome evolution. In particular, satellite-DNA and other repetitive-DNA sequences have proved to be powerful markers for these types of evolutionary studies (Heslop-Harrison, 2000; Navajas-Pérez et al., 2005b, 2006; Mariotti et al., 2006; Cuñado et al., 2007).

Satellite-DNA sequences are non-coding highly repetitive tandem arrayed sequences originally so named because they form shoulders - satellites - in density buoyant gradients if their AT versus GC content is significantly different from the bulk DNA, but later extended to all highly repeated tandemly organized sequences (Beridze, 1986). Together with retrotransposon-like dispersed sequences, they represent most of the DNA content in plants (Heslop-Harrison, 2000). Satellite-DNA sequences are located at heterochromatin which is found mostly in centromeric and subtelomeric regions in the chromosomes, but also at intercalary positions (reviewed in Sharma and Raina, 2005). Within satellite-DNA families, sub- telomeric satellites are repetitive sequences adjacent to telomeres that have been referred to as telomere-associated sequences or TASs (Louis and Vershinin, 2005) which in addition to location have several specific characteristics such as the presence of telomere degenerated motifs within the repeat sequence and the ineffectiveness of sequence homogenization events (Contento et al., 2005).

In the present study, we analyze a new satellite-DNA family isolated from $R$. induratus, RUSI, comprised of 170 -bp repeats. RUSI sequences are tandemly located in subtelomeric positions of most of the chromosomes of the species, with centromeric sites in some of them, and have main features to be regarded as TASs.

\section{Materials and methods}

Seeds and leaves of $R$. induratus were collected from a natural population in Padul, Granada (Spain). Seeds were kept in a cold and dry place until germination and leaves sampled from up to ten individuals were stored at $-80^{\circ} \mathrm{C}$ for further analysis. DNA isolation was performed using the Plant DNAzol kit (Invitrogen) following the manufacturer's recommendations. DNA from the following species was isolated previously and includes $R$. acetosa, $R$. intermedius, $R$. thyrsoides, $R$. tuberosus, $R$. suffruticosus, $R$. acetosella, $R$. hastatulus (Texas race and North Carolina race), $R$. bu- 
cephalophorus, R. scutatus, $R$. lunaria, R. maderensis, $R$. roseus, $R$. vesicarius, $R$. conglomeratus, $R$. crispus, $R$. patientia, $R$. obtusifolius and $R$. pulcher, collected from different sources (for systematics and locations, see Fig. 1 and Navajas-Pérez et al., 2005a).

RUSI satellite-DNA was isolated after restriction analysis from $R$. induratus total genomic DNA using BglI restriction endonuclease and electrophoresis in agarose gel with ethidium bromide. The most prominent bands visible under UV light were excised from the gel and purified using GFX ${ }^{\mathrm{TM}}$ PCR DNA and Gel Band Purification Kit (Amersham Biosciences). Purified BglI fragments were then ligated to the BamHI compatible ends of the pUC18 vector and cloned in competent DH5- $\alpha$ cells (Gibco BRL). Minipreparations were made using Perfectprep ${ }^{\circledR}$ Plasmid Mini (Eppendorf) and recombinant plasmids carrying the monomeric sequences were identified after screening with the purified band by dot-blot hybridization.

For Southern-blot (all the species listed in the first paragraph of this section were checked for the presence of RUSI sequences by the Southern-blot hybridization technique) and dot-blot hybridization and fluorescent in situ hybridization (FISH), a plasmid insert of clone RUSI_19 was used as a probe. Southern-blot and dot-blot hybridizations were carried out following GarridoRamos et al. (1999). For FISH, chromosome preparations were made following Schwarzacher and Heslop-Harrison (2000). Probe was labeled with biotin-dUTP by random priming according to the specifications of the Random Primer Labelling System (Invitrogen). Labeled probe (25-50 ng) was added to the hybridization mixture (50\% formamide, $2 \times$ SSC, $20 \%$ dextran sulphate, $0.125 \%$ SDS and 0.125 mM EDTA) (see Schwarzacher and Heslop-Harrison, 2000). Combined denaturation of the probe and chromosomal DNA was performed at $80^{\circ} \mathrm{C}$ for 8 min using a ThermoHybaid HyPro-20 and re-annealed at $37^{\circ} \mathrm{C}$ overnight. Stringent washes $\left(20 \%\right.$ formamide and $0.1 \times \mathrm{SSC}$ at $\left.42^{\circ} \mathrm{C}\right)$ were made prior to detection. Probe was detected with Alexa594/streptavidin (Molecular Probes, $0.5 \mathrm{ng} / \mathrm{ml}$ ) in 5\% (w/v) Bovine Serum Albumin (BSA) in $4 \times$ SSC, $0.2 \%$ Tween 20 following Schwarzacher and Heslop-Harrison (2000). Preparations were counterstained with 4,6-diamidino-2-phenylindole (DAPI, $2 \mu \mathrm{g} / \mathrm{ml}$ ) and mounted in antifade solution. Preparations were analyzed with a Zeiss Axioplan 2 epifluorescence microscope (Oberkochen, Germany) with suitable filters and photographed with a CCD camera (Optronics, model s97790). Colour figures and overlays were prepared with Adobe Photoshop 7.0 software, using only those processing functions that are applied to all pixels of the image. Karyotyping was performed according to a classical orcein staining method for $4-5 \mathrm{~h}$ followed by mounting preparations in $45 \%$ acetic acid.

For amplification of RUSI sequences in R. scutatus, we designed the pair of specific primers RUSI-A, 5'-CGAGTTTCACTTATTTGTCC-3', and RUSI-B, 5'-AAGTATACAAATTCAACCTT- $3^{\prime}$, from the sequences isolated in $R$. induratus. Presence/absence status in the rest of species was also screened using the same primer combination. PCR amplifications were carried out in 50 $\mu \mathrm{l}$ reactions containing $10 \mathrm{ng}$ of purified DNA, $2 \mathrm{mM}$ of dNTPs, $2 \mathrm{mM}$ of each primer and 1.25 units of Taq polymerase in $10 \mathrm{mM}$ Tris $\mathrm{HCl}$ at $\mathrm{pH} 8.3,5 \mathrm{mM} \mathrm{KCl}, 2 \mathrm{mM} \mathrm{MgCl}_{2}$ reaction buffer. Thermal cycles consisted of $1 \mathrm{~min}$ at $94^{\circ} \mathrm{C}, 1 \mathrm{~min}$ at $55^{\circ} \mathrm{C}$ and $1 \mathrm{~min}$ at $72^{\circ} \mathrm{C}$. The PCR products were electrophoresed in agarose gels, thereafter the bands were cut out of the gel, purified and ligated to the cloning plasmid pGEM-Teasy (Promega) and cloned in
Escherichia coli JM109 competent cells (Promega) following the manufacturer's instructions.

Recombinant clones belonging to both a pUC18 and a pGEM library were sequenced by the dideoxy-sequencing method using the automatic ABI-Prism 377 sequencer (Applied Biosystems). The EMBL accession numbers for all the sequences analyzed in this paper are: AM398567 to AM398599.

For sequence analysis, multiple alignments were performed using Clustal X (Thompson et al., 1997) followed by manual adjustments. Basic sequence evolutionary calculations, as well as the detection of transition stages of satellite-DNA evolution (Strachan et al., 1985) and shared and non-shared polymorphisms were performed by the software satDNA Analyzer (Navajas-Pérez et al., 2007). Additionally, a Perl script able to recognize regular expressions in both strands was written to search specifically for degenerated telomere motifs.

\section{Results}

\section{Isolation and organization of a new satellite-DNA family in $R$. induratus}

When total genomic DNA of $R$. induratus was digested with BglI and electrophoresed in agarose gels stained with ethidium bromide, several prominent bands of 170-bp fold units were observed (not shown). We isolated and cloned these 170-bp fragments as candidate repeat units of a satellite-DNA family and 16 clones were selected for sequencing. One of these clones (RUSI_19) was used as a probe for Southern blot hybridization against the genomic DNA of $R$. induratus digested with different restriction enzymes. A typical ladder pattern with a repeat unit of $170 \mathrm{bp}$ was detected for enzymes DraI and BglI suggesting tandem repeat organization typical for satellite-DNA. In the case of enzymes EcoRI and HindIII a type B ladder-pattern was detected (Fig. 2, lanes 1-4).

DNA sequence analysis, showed that the $16 \mathrm{Bg} / \mathrm{I}$ repeats analyzed ranged from 167 to $182 \mathrm{bp}$ in length, with an AT content of $67 \%$. The mean percentage of variation among these sequences is $15 \%$. Significantly, degenerated variants of the Arabidopsis-like TTTAGGG telomere repetitive motif matching the formula (TT)nAN(GG)n, were detected in both forward and reverse sense in most of the monomeric sequences (Fig. 3). No significant positive matches were detected when sequences were contrasted with the NCBI/EMBL database (July, 2008 release). Thus, they were considered to be a new satelliteDNA family, that we named RUSI (RUmex Scutati section Induratus species sequence). 


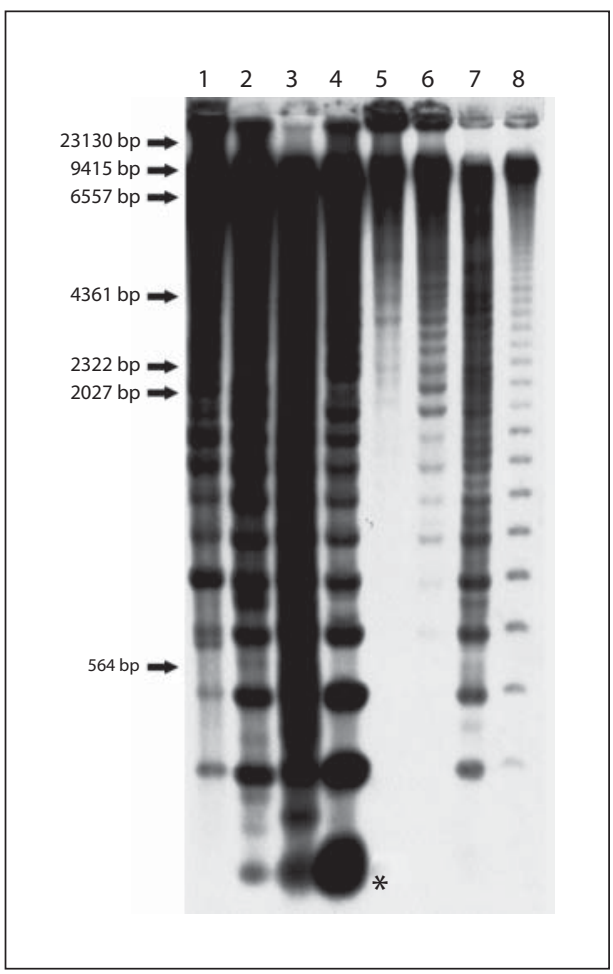

Fig. 2. Southern blot hybridization of RUSI sequences against total genomic DNA of Rumex induratus and Rumex scutatus digested with EcoRI $(1,5)$, HindIII $(2,6), \operatorname{DraI}(3,7)$ and $\operatorname{BglI}(4,8)$ restriction enzymes. Size markers are indicated on the left. $\left(^{*}\right)$ indicate monomeric repetitive unit (170 bp).

Chromosomal analysis and location of RUSI in

$R$. induratus karyotype

$R$. induratus is tetraploid, with a karyotype composed of $2 n=40$. According to the chromosomal morphology and the fluorescent in situ hybridization (FISH) pattern of RUSI sequences, the karyotype of $R$. induratus can be grouped in two complements of ten chromosome pairs, six meta-/submetacentric and four subtelocentric pairs each confirming the basic chromosome number of the group, $x=10$ (Figs. 4 and 5) (Navajas-Pérez et al., 2005a). Clusters of RUSI sequences are located in most of the larger chromosomes of $R$. induratus, mainly in subtelomeric positions. Subtelomeric/distal FISH signals were found either in one arm or in both arms depending on the chromosome. Additionally, a few chromosomes show hybridization signals indicating the presence of RUSI sequences in the centromeric region, exclusively or in addition to the subtelomeric sites. We then found subtelomeric/distal FISH signal of: (1) both arms in the two homeologous chromosome pairs I; (2) in the short arm of the two homeologous pairs III and IV; (3) in the long arm of the two homeologous pairs VI and VII. Pairs II and V in both sets and pair III of one set show paracentromeric hybridization signal indicating the presence of RUSI sequences in the centromeric region exclusively, but strongly (pairs II) or weaker and in addition to the subtelomeric sites (pairs III and V). Homeologous chromosome pairs VIII to X have no evidence of hybridization (Fig. 5).

\section{Interspecific analysis of RUSI sequences}

We screened the distribution of this new satellite-DNA family in representative species of the four subgenera of genus Rumex (López González, 1990). For that, we blotted onto a nylon membrane total genomic DNA digested with EcoRI of Rumex species listed in Fig. 1. Southern-blot hybridization with the RUSI_19 clone gave a positive signal only in $R$. scutatus and in the positive control $R$. induratus. These results agree with additional PCR experiments using specific primers for RUSI sequences (not shown). The pattern of hybridization in R. scutatus was slightly different from that of $R$. induratus since all restriction enzymes used in Southern-blot hybridization experiments gave a type B ladder pattern (Fig. 2, lanes 5-8).

From PCR experiments, a total of 17 RUSI monomeric sequences were obtained from $R$. scutatus. These sequences showed the same features described for $R$. induratus, including an average size of $170 \mathrm{bp}$ and a high AT content (66.7\%). The degree of intraspecific identity was $7.5 \%$. As in $R$. induratus, we also detected the presence of (TT)nAN(GG)n degenerated telomere motifs (Fig. 3).

For interspecific sequence comparison monomeric sequences isolated from $R$. induratus and $R$. scutatus were aligned requiring a 188-character dataset due to the inclusion of some indels as a consequence of insertions/deletions. The degree of interspecific divergence among sequences belonging to both species was $12 \%$. A tree generated using an $\mathrm{NJ}$ approach does not reveal the existence of highly supported clades of sequences, which do not appear clustered according to taxonomic affinity (not shown). The study of the alignment position per position for the analysis of the different stages toward the homogenization according to Strachan's model (Strachan et al., 1985; Navajas-Pérez et al., 2007) revealed the lack of positions between transition stages IV to VI. Up to 65 (35\%) positions were detected to be among II and III transition stages, while 35 (19\%) of the positions represented shared polymorphic positions between the two species (Table 1). Therefore, no species-specific variants were detected and, in fact, consensus sequences were identical between the two species. 


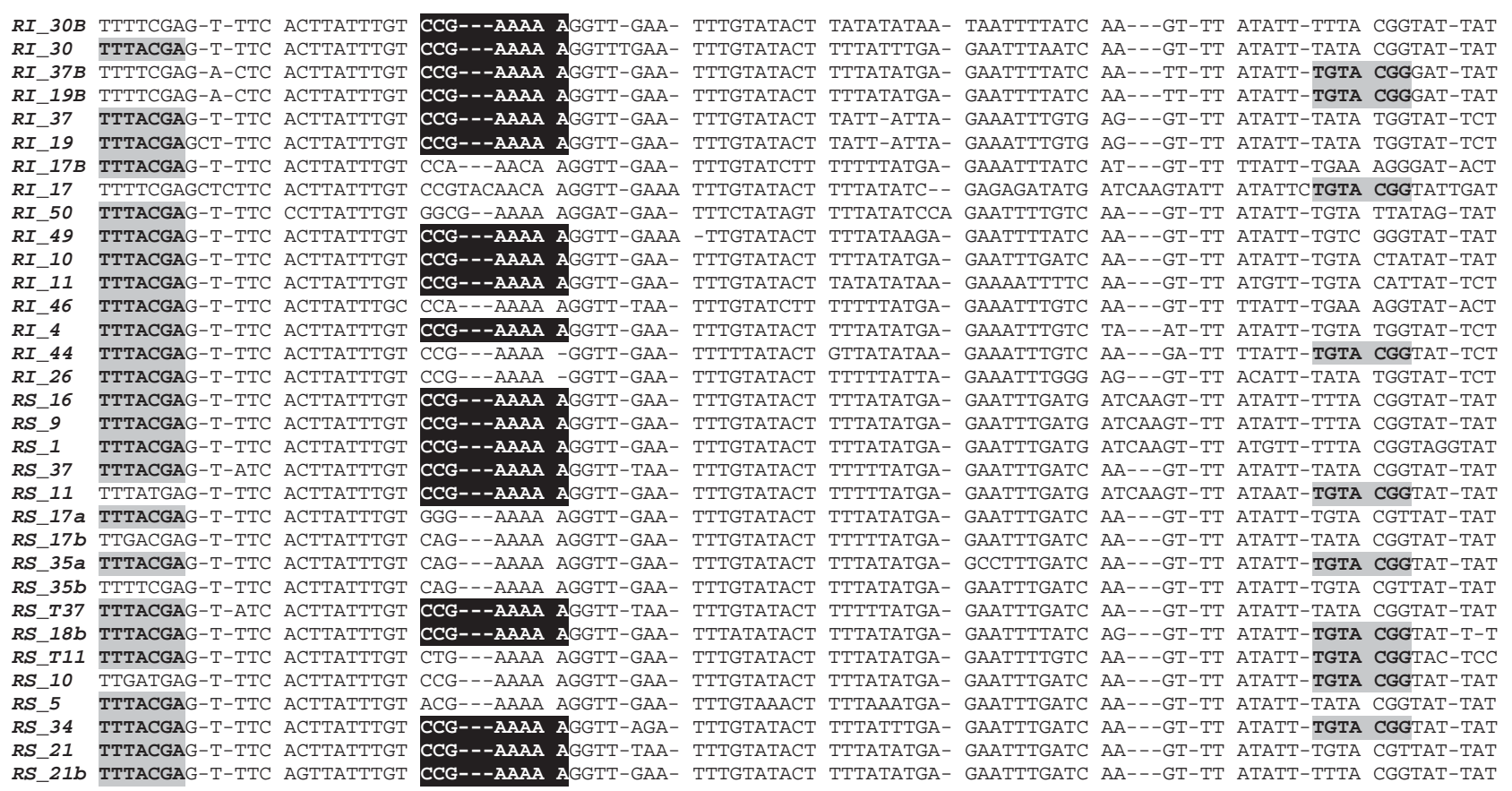

RI 30B A-TGACTGGT AGAATAAATT ATAT-TGAAT TTTGTTTATC TTAAAAATAT GCAA-TAAGT TCAAAGGGGG -TAGTACAAA CGT RI_30 A-AGACTGAT AGAATAAATT ATAT-TGAAA TTTTTTTATC TTCAAAAAAA ACAA-AATGT TCAAAGGGG -TAGTACACG GTT RI_37B A-AGACTGAT AGA-TAAATT ATAT-TGAAT TTGTTTTATA TTCAAATTAT GCAA-AAAGT TCAAAGGGG -TAGTACATG GTT RI_19B A-AGACTGAT AGA-TAAATT ATAT-TGAAT TTGTTTTATA TTCAAATTAT GCAA-AAAGT TCAAAGGGGG -TAGTACATG GTT RI 37 A-ATATCAAT GCAATAAAAT ATAT-TGAAT TTTTTTTATA TTCAAAATAT TCCA-AAAGT TCAAAGGGTA -TAGTACACG CTT RI 19 A-ATATCAAT GCAATAAAAT ATAT-TGAAT TTTTTTTATA TTCAAAATAT TCCA-AAAGT TCAAAGGGTA -TAGTACACG CTT RI_17B A-AGATTAAT AGAATAAATT TAAT-TGAAT TTTGTTTATC TTCAAAATAT GTTA-AAAGT TCAAAGGGGG -TAGTACGCG CTT RI_17 ACAGACTGAT AGA-TAAATT ATATATGAAT TTGTTTTATC TTCAGATTAT GCTAGAAAGT TCAAAGGGG -TAGTACACA CTT RI_50 A-AGACTAAT AGAATAAATT ATAT-TGAAT TTTTTTTATC TTCAAAATAT GCAA-AAATT TCAAAGGGTG -TAGTACACG CTT RI 49 A-AGACTGAT AGAATAAATT ATAT-TGAAT TTTGTTTATT TTTAAAATAT GCAA-AAATT TCAAAGCG-G -TAGTACACG CTT RI_10 A-AGACTGAT AGA-TAAATT ATAT-TGAAT TTT-TTTATC TTCAAAATAT GCAA-AAAGT GCAAAGGGGG -TAGTACACG GTT RI_11 A-AGTCTAAT AGAATAAATT GTAT-TGAAT TTTGTTTATC TTCAAAATAT GCAA-AAAGT TCAAAGGGG -TAGTACACG CTT RI_46 A-AGATTAAT AGAATAAATT TAAT-TGATT TTTTTTTATC TTCAAAATAT TTAA-AAAGT TCAAAGGGG - TAATACACG CAT RI_4 A-AGATTAAT GGAATAAATT AAAT-TGAAT TATTATAATC TTCAAAATAT TCAA-AAAGT TCAAAGGGG -TAGTACACA CTT RI 44 A-AAATTAAC AGAATAAATT AAAT-TGAAT TTAGTTTA-C TTGGAAATAT TCAA-AAAGT TCAAAGGGTG -TAGTTGACA CTT RI 26 A-ATATCAAT TCAATAAACT ATAT-TGAAT TTTGTTTATA TTCAAAATAT TCCA-AAAGT TCAAAGGGTG ATAGTACACG CTT RS_16 A-AGACTGAT AGAATAAATT ATAT-AGAAT TTATTTTATC ATCAAAATAT GCAA-AAAGT TCAAAGGGG -TAGTACACG GTT RS_9 A-AGACTGAT AGAATAATTT ATAT-AGAAT TTATTTTATC ATCAAAATAT GCAA-AAAGT TCAAAGGGG - TAGTACACG GAT RS 1 A-AGACT-AT AGAATAAATT ATAT-AGAAT TTATTTTATC ATCAAAATAT GCAA-AAAGT TCAAAGGGG -TAGTACACG GTT RS 37 A-AGACTGAT AGAATAAATT ATAT-TGAAT TTTTTTTATC TTCAAAATAT GCAA-AATGT TCAAAGGGGG - TAGTACACG GTT RS_11 A-AGACTGAT GAAATAAATT ATAT-TGAAT TTTTTTTATC TTCAAAATAT GCAA-AAAGT TCAATGGGG - -TAGTACACG CTT RS_17a A-AGACTGAT AGAATAATAT ATAT-TGAAT TTTGTTTATC TTCAAAATAT GCAA-AAAGT TCAGAGGGG -TAGTACACA TTT RS_17b A-AGACTGAT AGAATAAATT ATAT-TGAAT TTTTTTAATC TTCAAAATAT GCAA-AAAGT TCAAAGGGG- TTAGTACACG TTT RS 35a A-AGACTGAT AGA-TAAATT ATAT-TGAAT TT--TTTATC TTCAAAATAT GCAA-AAAGT GCAAAGGGGG GTAGTACATG GTT $\boldsymbol{R} \boldsymbol{S} \mathbf{3 5} \boldsymbol{b}$ A-AGACTGAT AGAATATATT ATAT-TGAAT TTTTTTTATC TCCAAAATAT GCAA-AAAGT TCAAAGGGGG - TAGTACACG CTT RS_T37 A-AGACTGAT AGAATAAATT ATAT-TGAAT TTTTTTTATC TTCAAAATAT GCAA-AATGT TCAAAGGGGG -TAGTACACG GTT RS_18b A-AGAATGAT GGAATAAAGA ATAT-TGAAT TTGTTTTATC TTGAAAATAT GCAA-AAAGT TCAAAGGGG -TAATACATG CTT RS_T11 A-AGACTAAT GGAATAAATT ATAT-TGAAT TTTGTTTATC TTCAAAATAT GCAA-AAAGT TCAAAGGGGG -TAGTACACG CTT RS 10 A-AGACTGAT AGAATAAATT ATAT-AGAAT TTAGTTTATC TCCAAAATAT GCAA-AAAGT TCAAAGGGGG -TAGTACACG CTT RS_5 A-AGACGGAT AGAATAAATT ATAT-TGAAT TTTGTTTATC TTCTAAATAT GCAA-AAAGT TCAAAGGTGG - TAGTACACG GTT RS_34 A-AGACTGGT AGA-TAAATT ATAT-TGAAT TT--TTTATC TTCAAAATAT GCAA-AAAGT GCAAAGGGG -TATTACACG GTT RS_21 A-AGACTGAT AGAATAATAT ATAT-TGAAT TTTGTTTATC TTCAAAATAT GCTA-AAAGT TCAAAGGGG - TAGTACACG TTT RS 21b A-AGACTGAT AAAATAAATT ATAA-TGAAT TTTGTTTATC TTCAAAATAT GCAA-AAATT TCAATGGGGG -TAGTACACT CTT

Fig. 3. Alignment of $R$. induratus and $R$. scutatus RUSI sequences. Shaded nucleotides indicate degenerated variants of the Arabidopsis-like TTTAGGG telomere repetitive motif in both forward (grey) and reverse (black) senses. 
Fig. 4. Karyotype of $R$. induratus. Note the presence of 20 chromosome pairs ordered in two ten-pair complements (A, B), corresponding to the basic chromosome number of the group, $\mathrm{x}=10$.

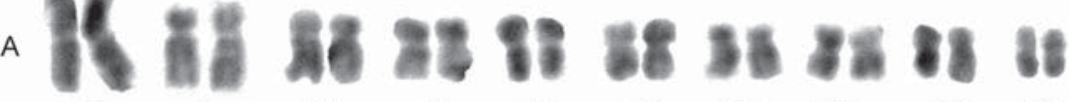 I II \\ B

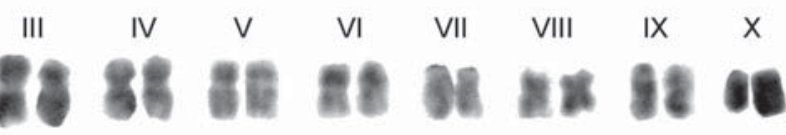

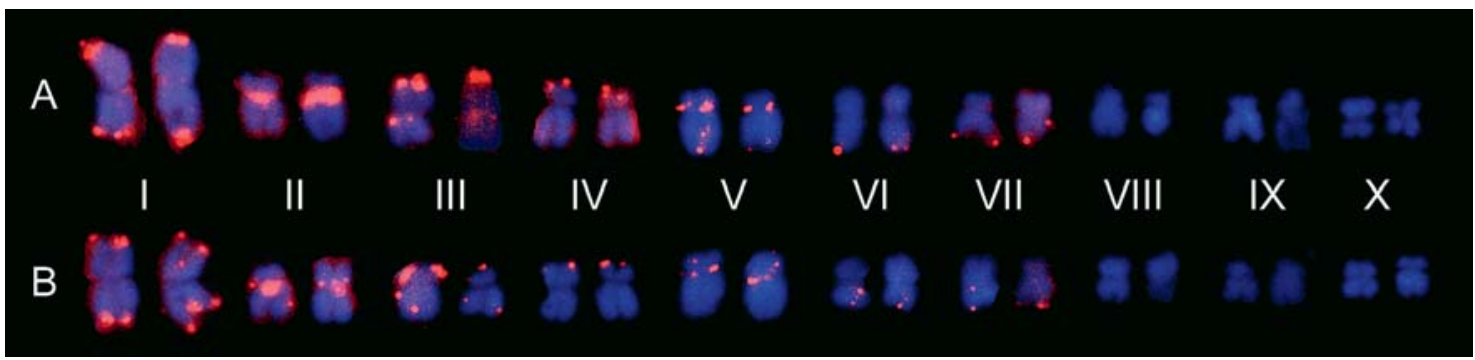

Fig. 5. Composite karyotype of $R$. induratus metaphase chromosomes (A, B) analyzed after FISH with RUSI sequences.

Table 1. Statistics for RUSI satellite-DNA sequences, including intraspecific and interspecific mean distances between monomeric sequences. The differences between species are stated as Fixed positions for fixed or nearly fixed polymorphisms while Transitional positions represent intermediate stages in the process of homogenization toward the fixation, according to the Strachan et al. (1985) method (Navajas-Pérez et al., 2007).

\begin{tabular}{lllll}
\hline Mean distance & & \multicolumn{2}{c}{ Differences between species } \\
\cline { 1 - 2 } $\begin{array}{l}\text { Intraspecific } \\
\text { (R. induratus/R. } \text { scutatus) }\end{array}$ & $\begin{array}{l}\text { Inter- } \\
\text { specific }\end{array}$ & $\begin{array}{l}\text { Fixed } \\
\text { (IV-V) }\end{array}$ & $\begin{array}{l}\text { Transitional } \\
\text { (II-III) }\end{array}$ \\
\hline 0.15 & 0.075 & 0.12 & 0 & 65 \\
\hline
\end{tabular}

\section{Discussion}

$R$. induratus is an endemic polygamous species of the Iberian Peninsula. This species is tetraploid (FernándezCasas, 1977) while the widespread closely related $R$. scutatus is diploid (Rechinger, 1964). In the present study, we have confirmed a karyotype of $2 \mathrm{n}=4 \mathrm{x}=40$ for $R$. induratus, with a basic chromosome number of $\mathrm{x}=10$ (Figs. 4 and 5). This basic chromosome number has been found to be the ancestral number in all docks and in most of the hermaphroditic and polygamous species of sorrels (De- graeve, 1975; Navajas-Pérez et al., 2005a). Recently, we have identified that, within the clade of polygamous and hermaphroditic sorrels, there are two major subclades, one of them contains the species $R$. scutatus and $R$. induratus in the Scutati section (subgenus Acetosa) and R. maderensis in the Hastati section (Acetosa) (Navajas-Pérez et al., 2005a). The macaronesian endemic $R$. maderensis is diploid and a basal species of the phylogenetic clade containing these three species. Thus, the tetraploidy of $R$. induratus can be interpreted as a derived character state that evolved in this clade independently of other polyploidization events occurring in other Rumex lineages.

In this species we describe here for the first time a new satellite-DNA family, RUSI. This satellite-DNA is located at the subtelomeric regions of most chromosomes of the karyotype (Fig. 5). Within the distal regions of the chromosomes in most eukaryotic species we can distinguish two differentiated parts. The more distal regions represent the true telomere and, except in rare exceptions, are formed of a variable number of short tandem repeats (Blackburn and Greider, 1995). In vertebrate species, the sequence TTAGGG is conserved at telomeres while in invertebrate species-specific variations of the sequence TTGGGG first described in Tetrahymena are present. In Arabidopsis, as well as in the vast majority of flowering plants analyzed up to date, TTTAGGG is the most com- 
mon repetitive telomere sequence (Richards and Ausubel, 1988). The subterminal sequences adjacent to the telomeres have been referred to as telomere-associated sequences or TASs (Louis and Vershinin, 2005) and are usually composed of a variety of highly tandem repetitive DNA sequences or satellite DNAs. In plants, TASs are often structurally more variable and polymorphic than any other regions of the genome even in species where they were described as not highly repeated, such as in rice and maize for example (Burr et al., 1992; Ashikawa et al., 1994). These subtelomeric sequences do not necessarily participate in telomere function but, for example, can facilitate meiotic pairing or protect terminal genes against the loss and gain processes at the chromosome ends (Henderson, 1995; Kipling, 1995). They could also be involved in the regulation of subtelomeric genes (Sykorova et al., 2003). On the other hand, these sequences have been postulated to acquire vital importance when telomere sequences disappear. In fact, chromosomes with depleted telomeres have a propensity to be lost (Sandell and Zakian, 1993). In this sense, several cases of a satellite DNA adopting the telomere-repeat role have been reported, as for instance the substitution of most telomere repeats of Alliaceae by rDNA sequences, retrotransposable elements and satellite-DNA sequences (Barnes et al., 1985; Pich and Schubert, 1998; Do et al., 2001). Subtelomeric sequences are not conserved, but are often species specific with a variety of lengths and degrees of repetitiveness (Kipling, 1995; Pryde et al., 1997), even existing as different satellite-DNA families (Brown, 1989; Brown et al., 1990; Weber et al., 1990, 1991) or subfamilies of the same satellite DNA (Kazama et al., 2006) in different subsets of chromosomes within a species. A common characteristic of subtelomeric satellite DNAs is the direct proximity to telomere repeats as in tobacco (Fajkus et al., 1995), Silene (Garrido-Ramos et al., 1999), or Triticeae (Contento et al., 2005) which lead to the intermixing of subtelomeric repeats with telomere sequence that are often degenerate. Also, subtelomeric repeats often show inverted organization with head to head orientation (Vershinin et al., 1995; Contento et al., 2005). The intimate contact of RUSI repeats with the telomere is corroborated by the presence of degenerated telomere motifs intercalated with them and might represent a common feature that occurs as a consequence of dynamic processes taking place at chromosome ends.

Interestingly, the RUSI repeats are not only located at the telomeres but also at centromeric positions of some chromosomes (Fig. 5). Also interestingly, there are differences between chromosomes having subtelomeric RUSI repeats on one or both arms. These observations lead to the consideration of chromosome reorganization implying that some loss/gain processes may have occurred. This report represents an important exception to the equilocality principle of satellite-DNA distribution (Thomas, 1971). Presence of the same type of satelliteDNA sequences at both centromeric and subtelomeric sequences can be explained by chromosome reorganization such as Robertsonian translocations (Garagna et al., 2002; Castiglia et al., 2006) or by transposition (Abad and Villasante, 2000; Tek and Jiang, 2004; Bao et al., 2006). Reported cases of alteration of the equilocal distribution of satellite DNAs also included satellite-DNA amplifications in specific regions of particular chromosomes such as sex chromosomes (Cuñado et al., 2007), B chromosomes (Alfenito and Birchler, 1993) or microchromosomes (Kuhn et al., 2007) or exceptional cases of independent evolution of interstitial heterochromatic regions of one chromosome pair with respect to the rest of the heterochromatic regions of the karyotype, leading to the characteristic asymmetries found in the genus Muscari (de la Herrán et al., 2001). In the case described here, the appearance of RUSI sequences in two non-equilocal different regions of the chromosomes of $R$. induratus could imply chromosome reorganization such as inversions and/or transpositions, but also Robertsonian translocations.

Satellite-DNA families have been found to be irregularly distributed within the different groups of plants, including chromosome-specific ones, such as the WE35 family of Triticum aestivum (Ueng et al., 2000), speciesspecific families, as RAYSI Y-specific satellite DNA in several Rumex species (Navajas-Pérez et al., 2006) or satellite DNA borne by species from a whole tribe, such as the subtelomeric 120-bp repeat family of Triticeae (Contento et al., 2005). Assuming that two species bearing the same sequence would be more related to each other than those lacking these sequences, satellite DNA can be used as a cladistic marker by merely analysing the presence/absence status. Here, we have detected that the RUSI satellite-DNA family is exclusively distributed in two species of the genus Rumex, R. induratus and R. scutatus. Both classical and more novel systematics of the genus (López González, 2000; Navajas-Pérez et al., 2005a) describe these two species as closely related to each other as part of the section Scutati of the subgenus Acetosa. Since we have not found evidence of RUSI sequences in any other Rumex species analyzed (not shown), including those more phylogenetically related as $R$. maderensis, the present study demonstrates that this satellite DNA originated very recently (be- 
tween 2.5 and 4.5 mya - Navajas-Pérez et al., 2005a). This is not an uncommon situation due to the high turnover rate of this part of the eukaryotic genome. Studies on satellite DNA dynamics explain loss or increase in copy number through not always well-known amplification mechanisms in a relatively short evolutionary time (Charlesworth et al., 1994).

Repetitive-DNA families are influenced by several molecular mechanisms of non-reciprocal exchange such as unequal crossing-over or gene conversion (Ohta and Dover, 1984) that can gradually spread a variant sequence throughout a family within a sexual population in a population-genetic process called molecular drive (Dover, 2002). Molecular drive leads to high homogeneity levels in a repetitive DNA family for species-diagnostic mutations, which subsequently is the origin of inter-species genetic divergence, an evolutionary pattern of repetitive sequences known as concerted evolution (Dover, 2002). Many empirical observations indicate that the rate of production of new sequence variants (mutations) in satellite-DNA sequences is a slower process than their rate of spread, while the general paucity of transition stages indicates also that the replacement is relatively fast (Ugarković and Plohl, 2002). However, this is not occurring for RUSI sequences since we detected high levels of intraspecific sequence variation (i.e., low rates of intraspecific sequence homogenization; Table 1). The intra- specific sequence variation has two sources: on one hand, a high percentage of shared polymorphisms between $R$. induratus and R. scutatus (19\%), which might represent ancestral polymorphisms; on the other hand, a much higher percentage of new species-specific mutations (35\% of transition stages II+III) representing an initial process of sequence divergence between the two species (mean sequence differences of 12\%). However, spreading rates do not appear to operate at higher rates than mutation rates, a fact that could be explained as a consequence of the multichromosomal and multiloci distribution (i.e., chromosomal rearrangements) of RUSI sequences. Multichromosomal distribution and chromosomal rearrangements together with polyploidy (Krieger and Fuerst, 2002) might be among the possible causes for extensive intraspecific variability of repetitive sequences of various organisms. Polyploidization is also a fact to be considered here since we have found higher levels of variation in the tetraploid $R$. induratus than in the diploid R. scutatus.

\section{Acknowledgements}

We thank Dr John Bailey, University of Leicester, for checking the English of the manuscript.

\section{References}

-Abad JP, Villasante A: Searching for a common centromeric structural motif: Drosophila centromeric satellite DNAs show propensity to form telomeric-like unusual DNA structures. Genetica 109:71-75 (2000).

-Alfenito MR, Birchler JA: Molecular characterization of a maize B chromosome centric sequence. Genetics 135:589-597 (1993).

-Ashikawa I, Kurata N, Nagamura Y, Minobe Y: Cloning and mapping of telomere-associated sequences from rice. DNA Res 1:67-76 (1994).

- Bao W, Zhang W, Yang Q, Zhang Y, Han B, et al: Diversity of centromeric repeats in two closely related wild rice species, Oryza officinalis and Oryza rhizomatis. Mol Genet Genomics 275:421-430 (2006).

Barnes SR, James AM, Jamieson G: The organisation, nucleotide sequence, and chromosomal distribution of a satellite DNA from Allium cepa. Chromosoma 92:185-192 (1985).

Beridze TG: Satellite DNA (Springer, Berlin 1986).
Blackburn EH, Greider CW: Telomeres (Cold Contento A, Heslop-Harrison JS, Schwarzacher Spring Harbor Laboratory Press, Cold Spring Harbor 1995).

Brown WRA: Molecular cloning of human telomeres in yeast. Nature 38:774-776 (1989).

Brown WRA, MacKinnon PJ, Villasanté A, Spurr N, Buckle VJ, et al: Structure and polymorphism of human telomere-associated DNA. Cell 63:119-132 (1990).

- Burr B, Burr FA, Matz EC, Romero-Severson J: Pinning down loose ends: mapping telomeres and factors affecting their length. Plant Cell 4:953-960 (1992).

Castiglia R, Garagna S, Merico V, Oguge N, Corti M: Cytogenetics of a new cytotype of African Mus (subgenus Nannomys) minutoides (Rodentia, Muridae) from Kenya: C- and Gbanding and distribution of (TTAGGG)n telomeric sequences. Chromosome Res 14: 587-594 (2006).

Charlesworth B, Sniegowski P, Stephan W: The evolutionary dynamics of repetitive DNA in eukaryotes. Nature 371:215-220 (1994). T: Diversity of a major repetitive DNA sequence in diploid and polyploid Triticeae. Cytogenet Genome Res 109:34-42 (2005).

- Cuñado N, Navajas-Pérez R, de la Herrán R, Ruiz Rejón C, Ruiz Rejón M, et al: The evolution of sex chromosomes in the genus Rumex (Polygonaceae): identification of a new species with heteromorphic sex chromosomes. Chromosome Res 15:825-832 (2007).

de la Herrán R, Robles F, Cuñado N, Santos JL, Ruiz Rejón M, et al: A heterochromatic satellite DNA is highly amplified in a single chromosome of Muscari (Hyacinthaceae). Chromosoma 110:197-202 (2001).

Degraeve N: Contribution à l'étude cytotaxonomique des Rumex. I. Le genre Rumex L. sensu stricto. Caryologia 28:187-201 (1975).

-Do GS, Seo BB, Yamamoto M, Suzuki G, Mukai $Y$ : Identification and chromosomal location of tandemly repeated DNA sequences in $\mathrm{Al}$ lium cepa. Genes Genet Syst 76:53-60 (2001). 
Dover G: Molecular drive. Trends Genet 18:587- Louis EJ, Vershinin AV: Chromosome ends: dif589 (2002).

-Fajkus J, Kovarík A, Královics R, Bezděk M: Organization of telomeric and subtelomeric chromatin in the higher plant Nicotiana tabacum. Mol Gen Genet 247:633-638 (1995).

Fernández-Casas J: Números cromosómicos de plantas españolas, IV. Anales Inst Bot Cavanilles 34:335-349 (1977).

-Ferreres F, Ribeiro V, Izquierdo AG, Rodrigues MA, Seabra RM, et al: Rumex induratus leaves: interesting dietary source of potential bioactive compounds. J Agric Food Chem 54:5782-5789 (2006).

-Garagna S, Zuccotti M, Capanna E, Redi CA: High-resolution organization of mouse telomeric and pericentromeric DNA. Cytogenet Genome Res 96:125-129 (2002).

-Garrido-Ramos MA, de la Herrán R, Ruiz Rejón M, Ruiz Rejón C: A subtelomeric satellite DNA family isolated from the genome of the dioecious plant Silene latifolia. Genome 42: 442-446 (1999).

Henderson ER: Telomere DNA structure, in Blackburn EH, Greider CW (eds): Telomeres, pp 11-34 (Cold Spring Harbor Laboratory Press, Cold Spring Harbor 1995).

-Heslop-Harrison JS: Comparative genome organization in plants: from sequence and markers to chromatin and chromosomes. Plant Cell 12:617-635 (2000).

-Kazama Y, Sugiyama R, Suto Y, Uchida W, Kawano S: The clustering of four subfamilies of satellite DNA at individual chromosome ends in Silene latifolia. Genome 49:520-530 (2006).

Kipling D: The Telomere (Oxford University Press, New York 1995).

-Krieger J, Fuerst PA: Evidence for a slowed rate of molecular evolution in the order Acipenseriformes. Mol Biol Evol 19:891-897 (2002). Erratum in: Mol Biol Evol 19:1644 (2002).

Kuhn GCS, Franco FF, Manfrin MH, MoreiraFilho O, Sene FM: Low rates of homogenization of the DBC-150 satellite DNA family restricted to a single pair of microchromosomes in species from the Drosophila buzzatii cluster. Chromosome Res 15:457-469 (2007).

López González G: Género Rumex L., in Castroviejo S, Laínz M, López González G, Montserrat P, Muñoz Garmendia F, Paiva J, Villar L (eds): Flora Iberica, vol II, pp 595-634 (CSIC, Real Jardín Botánico de Madrid, Madrid 1990). ferent sequences may provide conserved functions. Bioessays 27:685-697 (2005).

Mariotti B, Navajas-Pérez R, Lozano R, Parker JS, de la Herrán R, et al: Cloning and characterization of dispersed repetitive DNA derived from microdissected sex chromosomes of Rumex acetosa. Genome 49:114-121 (2006).

-Moreno-Jiménez E, Gamarra R, Carpena-Ruiz RO, Millán R, Peñalosa JM, et al: Mercury bioaccumulation and phytotoxicity in two wild plant species of Almadén area. Chemosphere 63:1969-1973 (2006).

- Navajas-Pérez R, de la Herrán R, López González G, Jamilena M, Lozano R, et al: The evolution of reproductive systems and sex-determining mechanisms within Rumex (Polygonaceae) inferred from nuclear and chloroplastidial sequence data. Mol Biol Evol 22: 1929-1939 (2005a).

Navajas-Pérez R, de la Herrán R, Jamilena M, Lozano R, Ruiz Rejón C, et al: Reduced rates of sequence evolution of Y-linked satellite DNA in Rumex (Polygonaceae). J Mol Evol 60:391399 (2005b).

- Navajas-Pérez R, Schwarzacher T, de la Herrán R, Ruiz Rejón C, Ruiz Rejón M, Garrido-Ramos MA: The origin and evolution of the variability in a Y-specific satellite-DNA of Rumex acetosa and its relatives. Gene 368: 61-71 (2006).

- Navajas-Pérez R, Rubio-Escudero C, Aznarte JL, Ruiz Rejón M, Garrido-Ramos MA: SatDNA Analyzer: a computing tool for satelliteDNA evolutionary analysis. Bioinformatics 23:767-768 (2007).

Ohta T, Dover GA: The cohesive population genetics of molecular drive. Genetics 108:501521 (1984).

Pich U, Schubert I: Terminal heterochromatin and alternative telomeric sequences in Allium cepa. Chromosome Res 6:315-321 (1998).

Pryde FE, Gorham HC, Louis EJ: Chromosome ends: all the same under their caps. Curr Opin Genet Dev 7:822-828 (1997).

Rechinger KH Jr: The genus Rumex L., in Tutin TG, Heywood VH, Burges NA, Valentine DH, Walters SM, Webb DA (eds): Flora Europaea, vol 1, pp 82-89 (Cambridge Univer-

Richards EJ, Ausubel FM: Isolation of a higher eukaryotic telomere from Arabidopsis thaliana. Cell 53:127-136 (1988).

-Rivera D, Obón C: The ethnopharmacology of Madeira and Porto Santo Islands, a review. J Ethnopharmacology 46:73-93 (1995). sity Press, Cambridge 1964).
Sandell LL, Zakian VA: Loss of a yeast telomere: arrest, recovery, and chromosome loss. Cell 75:729-739 (1993).

Schwarzacher T, Heslop-Harrison JS: Practical in situ Hybridization. (BIOS Scientific Publishers Limited, Oxford 2000).

-Sharma S, Raina SN: Organization and evolution of highly repeated satellite DNA sequences in plant chromosomes. Cytogenet Genome Res 109:15-26 (2005).

-Strachan T, Webb D, Dover GA: Transition stages of molecular drive in multiple-copy DNA families in Drosophila. EMBO J 4:1701-1708 (1985).

-Sykorova E, Lim KY, Chase MW, Knapp S, Leitch IJ, et al: The absence of Arabidopsis-type telomeres in Cestrum and closely related genera Vestia and Sessea (Solanaceae): first evidence from eudicots. Plant J 34:283-291 (2003).

Tek AL, Jiang J: The centromeric regions of potato chromosomes contain megabase-sized tandem arrays of telomere-similar sequence. Chromosoma 113:77-83 (2004).

Thomas CA Jr: The genetic organization of chromosomes. Annu Rev Genet 5:237-256 (1971).

Thompson JD, Gibson TJ, Plewniak F, Jeanmougin F, Higgins DG: The ClustalX windows interface: flexible strategies for multiple sequence alignment aided by quality analysis tools. Nucleic Acids Res 24:4876-4882 (1997).

-Ueng PP, Hang A, Tsang H, Vega JM, Wang L, et al: Molecular analyses of a repetitive DNA sequence in wheat (Triticum aestivum L.). Genome 43:556-563 (2000).

-Ugarković D, Plohl M: Variation in satellite DNA profiles - causes and effects. ЕMBO J 21: 5955-5959 (2002).

Vershinin AV, Schwarzacher T, Heslop-Harrison JS: The large-scale genomic organization of repetitive DNA families at the telomeres of rye chromosomes. Plant Cell 7:1823-1833 (1995).

-Weber B, Collins C, Robbins C, Magenis RE, Delaney AD, et al: Characterization and organization of DNA sequences adjacent to the human telomere associated repeat (TTAGGG)n. Nucleic Acids Res 18:33533361 (1990).

- Weber B, Allen L, Magenis RE, Hayden MR. A low-copy repeat located in subtelomeric regions of 14 different human chromosomal termini. Cytogenet Cell Genet 57:179-183 (1991). 